\title{
The use of microwave radiation for obtaining carbonaceous adsorbents from biomass and their use in elimination of inorganic pollutants
}

\author{
Justyna Kazmierczak-Razna $^{1} \cdot$ Robert Pietrzak $^{1}$
}

Received: 9 October 2015/Revised: 20 October 2015/Accepted: 2 November 2015/Published online: 6 November 2015

(C) The Author(s) 2015. This article is published with open access at Springerlink.com

\begin{abstract}
A new technology of obtaining activated carbons by physical and direct activation of biomass with the use of microwave radiation is described. The effect of activation temperature $\left(700\right.$ and $\left.800{ }^{\circ} \mathrm{C}\right)$ and two periods of time (15 and $30 \mathrm{~min}$ ) on the textural parameters, acidbase character of the surface and sorption properties of activated carbons was tested. The resulting carbons were characterized by low-temperature nitrogen sorption and determination of $\mathrm{pH}$ as well as the number of surface oxygen groups. The sorption properties of the activated carbons obtained were characterized by determination of nitrogen dioxide and hydrogen sulphide adsorption in dry and wet conditions as well as by iodine removal from aqueous solution. The final products were adsorbents of surface area ranging from 291 to $368 \mathrm{~m}^{2} / \mathrm{g}$ and pore volume from 0.20 to $0.26 \mathrm{~cm}^{3} / \mathrm{g}$, showing basic character of the surface. The results obtained in our study have proved that suitable choice of the pyrolysis and activation procedure for hay with the use of microwave radiation permit producing adsorbents with good capacity toward toxic gases of acidic character as well as inorganic pollutants of molecules of size similar to that of iodine molecules.
\end{abstract}

Keywords Biomass - Microwave radiation - Activated carbons $\cdot$ Iodine number $\cdot \mathrm{NO}_{2} / \mathrm{H}_{2} \mathrm{~S}$ adsorption

Justyna Kazmierczak-Razna

justykaz@amu.edu.pl

Robert Pietrzak

pietrob@amu.edu.pl

1 Laboratory of Applied Chemistry, Faculty of Chemistry, Adam Mickiewicz University in Poznań, Umultowska 89b, 61-614 Poznan, Poland

\section{Introduction}

Climate changes and the need to reduce the use of nonrenewable resources and energy have become the fundamental problems of our times. Their solution should improve the standard of life of the present and future generations. The issue of the natural environment protection has reached global character (Nowicki et al. 2012). The measures aimed at reducing the level of emission of pollution include development of new technologies and correct storage of waste products (Yuen and Hameed 2009). On the other hand, rapid development of economy and industry has brought a significant increase in the emission of nitrogen(IV) dioxide and hydrogen sulphide to the environment. These gases are highly toxic and harmful for humans and vegetation. Long-lasting exposure to these gases can cause irritation, nausea, problems with concentration and even death. In view of that, the legal rules on the maximum admissible levels of $\mathrm{NO}_{2}$ and $\mathrm{H}_{2} \mathrm{~S}$ concentrations are increasingly restrictive, which forced the need for monitoring of the level of these gases both in the natural environment and in certain workplaces (KazmierczakRazna et al. 2015a). The technologies developed to reduce or eliminate the emission of toxic gases have recently been using activated carbons whose very high adsorption capacity makes them attractive for removal of pollutants from the air (Nowicki and Pietrzak 2011; Nowicki et al. 2013, 2014; Guo et al. 2006; Hauchhum and Mahanta 2014; Adib et al. 1999; Bandosz 2002) and water (Nethaji et al. 2010; Ferrero 2007; Malik 2004; Pal and Deb 2014; Ahmad and Hameed 2010; Wu and Tseng 2008; Benadjemia et al. 2011).

Literature provides a large number of methods for the production of activated carbons, employing mainly conventional heating (Nowicki et al. 2008, 2009; Sych et al. 
2012; Puziy 2011; Malik et al. 2002). The drawbacks of this way of heating include non-uniform heating of the samples, long time of heating and high temperatures of carbonisation and activation, which means high energy consumption and thus high cost of production of carbonaceous materials (Jiang and Ma 2011; Remya and Lin 2011). That is why alternative methods have been proposed, among them the method based on the use of microwave radiation that has attracted much interest recently (Kazmierczak-Razna et al. 2015b; Li et al. 2008; Liu et al. 2010; Hesas et al. 2013).

The main aim of this work was to obtain a series of low cost activated carbons from hay with the use of microwave radiation as well as characterisation of their physicochemical and sorption properties towards gas phase pollutants represented by nitrogen dioxide and hydrogen sulphide and liquid phase pollutants represented by inorganic substances of molecules of size similar to that of iodine molecules. Different preparation parameters were examined in order to evaluate the influence of temperature and time of activation on the adsorption properties of the final product. Finally, we tried to correlate the surface properties with the ability of the activated carbons to remove a nitrogen dioxide and hydrogen sulphide and inorganic pollutant from water.

\section{Experimental section}

\subsection{Samples preparation}

The precursor of char was the post-agricultural wastelow quality hay in the form of cylinders of $0.8 \mathrm{~cm}$ in diameter and $1 \mathrm{~cm}$ in length. The initial material was subjected to pyrolysis (P) in a muffle chamber in a microwave furnace (Phoenix, CEM) under a stream of nitrogen with a flow rate of $0.170 \mathrm{~L} / \mathrm{min}$ in $700{ }^{\circ} \mathrm{C}(\mathrm{HP})$. In the microwave furnace used it is not possible to control the power consumed by the furnace. However, it was possible to control temperature by a thermocouple installed inside the muffle chamber. In the final temperature, sample was kept 60 min and then cooled down in inert atmosphere. The char obtained were next subjected to physical activation (A) in a microwave oven. This process was carried out at two temperatures 700 (HPA7) and $800{ }^{\circ} \mathrm{C}$ (HPA8), under a stream of carbon dioxide with a flow rate of $0.250 \mathrm{~L} / \mathrm{min}$, for 15 and $30 \mathrm{~min}$ (HPA7-15 or HPA7-30) and $800{ }^{\circ} \mathrm{C}$ (HPA8-15 or HPA830). Some part of the precursor was also subjected to direct activation (DA) with $\mathrm{CO}_{2}$, which was performed in the same conditions as physical activation (HDA7-15, HDA7-30, HDA8-15 and HDA8-30).

\subsection{Analytical procedures}

The elemental analysis of the activated carbons were performed on an elemental analyser CHNS Vario EL III (Elementar Analysensysteme GmbH, Germany).

The content of ash was performed according to the Data National Standards ISO 1171:2002. The dried sample was burned in a microwave oven at $850{ }^{\circ} \mathrm{C}$, for $60 \mathrm{~min}$. The ash content was expressed as: \%ASH $=($ (mass of crucible and ash - mass of crucible)/(mass of crucible and sample - mass of crucible) $) * 100 \%$.

Characterization of the pore structure of activated carbons was performed on the grounds of low-temperature nitrogen adsorption-desorption isotherms measured on Autosorb iQ surface area analyser (Quantachrome Instruments USA). On the grounds of results of the measurements BET surface area, total pore volume and pore diameter were determined. The $S_{\mathrm{BET}}$ surface area was assessed within the range of relative pressures from 0.05 to 0.3. The total pore volume $\left(V_{t}\right)$ was calculated by measuring the amount of liquid nitrogen adsorbed at a relative pressure $p / p_{0}=0.99$. The average pore diameter $(d)$ was calculated from equation $d=4 V_{t} / S_{\mathrm{BET}}$. Moreover micropore volume and micropore surface area were calculated using t-plot method.

The content of surface oxygen functional groups were determined by the Boehm method. $0.25 \mathrm{~g}$ of carbon sample was placed in $25 \mathrm{~mL}$ of $0.1 \mathrm{M}$ solutions of either sodium hydroxide or hydrochloric acid. The vials were sealed and shaken for $24 \mathrm{~h}$ and then $10 \mathrm{~mL}$ of each filtrate was pipetted and the excess of base or acid was titrated with $0.1 \mathrm{M} \mathrm{HCl}$ or $\mathrm{NaOH}$, as required. The numbers of acidic sites of various types were calculated under the assumption that $\mathrm{NaOH}$ neutralizes all acidic groups and $\mathrm{HCl}$ reacts with all basic group.

The $\mathrm{pH}$ surface of samples was determined with the following procedure: approximately $0.20 \mathrm{~g}$ of each sample were suspended on $10 \mathrm{~mL}$ of distilled water. Suspensions were stirred overnight to reach equilibrium and measuring the $\mathrm{pH}$ periodically until readings were constant.

\subsection{Adsorption studies}

\subsection{1 $\mathrm{H}_{2} \mathrm{~S}$ and $\mathrm{NO}_{2}$ adsorption}

The samples sieved to a particle size between 0.75 and $1.65 \mathrm{~mm}$ were packed into a glass column (length $300 \mathrm{~mm}$, internal diameter $9 \mathrm{~mm}$, bed volume $3 \mathrm{~cm}^{3}$ ). Dry or moist air (70\% humidity) with $0.1 \%$ of $\mathrm{H}_{2} \mathrm{~S}$ or $\mathrm{NO}_{2}$ was passed through the dry bed of the adsorbent at $0.450 \mathrm{~L} / \mathrm{min}$. The breakthrough of $\mathrm{H}_{2} \mathrm{~S}$ or $\mathrm{NO}_{2}$ were monitored using Q-RAE PLUS PGM-2000/2020 with electrochemical sensors. The tests were stopped at the breakthrough concentration of 
$100 \mathrm{ppm}$ (in case of $\mathrm{H}_{2} \mathrm{~S}$ ) or $20 \mathrm{ppm}$ (for $\mathrm{NO}_{2}$ ) because of the electrochemical sensor limits. The interaction capacities of each sorbent in terms of milligram of $\mathrm{H}_{2} \mathrm{~S}$ or $\mathrm{NO}_{2}$ per gram of adsorbent were calculated by integration of the area above the breakthrough curves, and from the toxic gas concentration in the inlet gas, flow rate, breakthrough time and mass of sorbent (Pietrzak and Bandosz 2007). Additionally to check the $\mathrm{NO}_{2}$ reduction, in a result at its reaction with carbonaceous material the concentration of $\mathrm{NO}$ in the system was also monitored till $200 \mathrm{ppm}$.

After the breakthrough tests, for $30 \mathrm{~min}$ (for $\mathrm{NO}_{2}$ ) and 5 min (for $\mathrm{H}_{2} \mathrm{~S}$ ) all samples were exposed to a flow of carrier air $(360 \mathrm{~mL} / \mathrm{min})$.

\subsubsection{Iodine adsorption}

Determination of the iodine adsorption was performed according to the ASTM D4607-94(2006) standard.

\section{Results and discussion}

\subsection{Elemental composition of the activated carbons}

The precursor used, hay $(\mathrm{H})$, is characterised with low content of carbon (48.1 wt \%), very high content of volatile matter (over $80 \mathrm{wt} \%$ ) and a low content of mineral substances (ash) of about $5.7 \%$. Therefore, in order to increase the degree of carbon content and reduce the content of volatile matter, one part of the precursor was subjected to direct activation, while the other part was at first subjected to pyrolysis at $700{ }^{\circ} \mathrm{C}$ and then by physical activation by $\mathrm{CO}_{2}$ in two different temperature and temporal variants.

Analysis of the data collected in Table 1 shows that the processes of activation, both the precursor and the char obtained from this precursor, cause significant changes in

Table 1 Elemental analysis of the activated carbons and the yield of activation process (wt\%)

\begin{tabular}{llllllll}
\hline Sample & Ash & $\mathrm{C}^{\text {daf1 }}$ & $\mathrm{H}^{\text {daf }}$ & $\mathrm{N}^{\text {daf }}$ & $\mathrm{S}^{\text {daf }}$ & $\mathrm{O}^{\text {daf2 }}$ & Yield \\
\hline HPA7-15 & 29.1 & 83.4 & 1.3 & 2.3 & 0.4 & 12.6 & 71.0 \\
HPA7-30 & 25.6 & 84.8 & 0.7 & 2.3 & 0.3 & 11.9 & 72.3 \\
HPA8-15 & 27.6 & 86.1 & 0.3 & 2.1 & 0.3 & 11.1 & 70.3 \\
HPA8-30 & 27.2 & 86.0 & 0.5 & 2.2 & 0.4 & 10.9 & 68.1 \\
HDA7-15 & 23.6 & 81.7 & 1.9 & 2.5 & 0.4 & 13.4 & 21.6 \\
HDA7-30 & 21.8 & 79.1 & 1.1 & 2.4 & 0.3 & 17.1 & 23.1 \\
HDA8-15 & 26.1 & 82.2 & 1.5 & 2.3 & 0.5 & 13.5 & 18.0 \\
HDA8-30 & 23.7 & 86.7 & 0.5 & 2.1 & 0.3 & 10.4 & 20.2 \\
\hline
\end{tabular}

${ }^{1}$ Dry-ash-free basis; ${ }^{2}$ determined by difference the structure of the precursor. The greatest changes with respect to the initial material, that is the greatest increase in the content of $\mathrm{C}^{\mathrm{daf}}$ and the greatest decrease in $\mathrm{O}^{\text {daf }}$, are observed for the samples subjected to direct activation at $800{ }^{\circ} \mathrm{C}$ for $30 \mathrm{~min}$ (HDA8-30), at which the processes of pyrolysis and activation take place simultaneously. The activates sample obtained in this way shows much higher content of carbon $\mathrm{C}^{\text {daf }}$, increased by $38.6 \mathrm{wt} \%$ and much lower content of $\mathrm{O}^{\mathrm{daf}}$, reduced by $33.8 \mathrm{wt} \%$, with respect to those of the precursor. Moreover, the higher the activation temperature, the greater the increase in the content of $\mathrm{C}^{\mathrm{daf}}$, while the lower the content of $\mathrm{O}^{\text {daf }}$. The thermochemical processing gives also a significant decrease in the content of hydrogen with respect to that in the precursor, the most pronounced decrease in the content of hydrogen was observed in the samples subjected to physical activation at $800^{\circ}$ for $15 \mathrm{~min}$ (HPA8-15). The activation causes also significant changes in the content of nitrogen and sulphur. In all samples after activation the content of these heteroatoms considerably increased with respect to their content in the precursor, which is a consequence of much decrease in the volatile matter and oxygen. On the basis of the data obtained, it can be concluded that the content of nitrogen and sulphur in all products of activation was at a similar level.

\subsection{Textural parameters of activated carbons}

According to the data presented in Table 2, irrespective of temperature and time of activation, the activated carbons obtained are characterised by not much developed surface area (from 291 to $368 \mathrm{~m}^{2} / \mathrm{g}$ ) and moderate pore volume $\left(0.20-0.26 \mathrm{~cm}^{3} / \mathrm{g}\right)$. Comparison of the data for particular samples implies that the textural parameters of the samples activated for $15 \mathrm{~min}$ are more beneficial than those of the samples activated for $30 \mathrm{~min}$, irrespectively of the temperature of activation. A possible reason is that a too long time of activation ( $30 \mathrm{~min}$ ) could be too drastic for the precursor used and cause burning of considerable amount of the organic substance and therefore, destruction of the porous structure of the materials obtained. The data from Table 2 also indicate that the temperature of activation influences the textural parameters of the samples. The activation at $800{ }^{\circ} \mathrm{C}$ has a beneficial effect on the surface area development only in the process of direct activation. All the samples subjected to physical activation have similar textural parameters. According to the data given in Table 2, the activated carbon samples are characterised by microporous structure as the contribution of micropores in the total pore volume varies from 72 to $83 \%$. The other part are small mesopores of diameters varying from 2.61 to $2.87 \mathrm{~nm}$. 
Table 2 Textural parameters of the activated carbons obtained

\begin{tabular}{|c|c|c|c|c|c|c|}
\hline Sample & $\begin{array}{l}\text { Total surface } \\
\text { area }\left(\mathrm{m}^{2} / \mathrm{g}\right)\end{array}$ & $\begin{array}{l}\text { Micropore } \\
\text { area }\left(\mathrm{m}^{2} / \mathrm{g}\right)\end{array}$ & $\begin{array}{l}\text { Total pore } \\
\text { volume }\left(\mathrm{cm}^{3} / \mathrm{g}\right)\end{array}$ & $\begin{array}{l}\text { Micropore } \\
\text { volume }\left(\mathrm{cm}^{3} / \mathrm{g}\right)\end{array}$ & $\mathrm{V}_{\text {mic }} / \mathrm{V}_{\mathrm{t}}$ & $\begin{array}{l}\text { Average pore } \\
\text { diameter }(\mathrm{nm})\end{array}$ \\
\hline HPA7-15 & 368 & 338 & 0.25 & 0.19 & 0.76 & 2.76 \\
\hline HPA7-30 & 354 & 325 & 0.25 & 0.18 & 0.72 & 2.80 \\
\hline HPA8-15 & 363 & 339 & 0.24 & 0.19 & 0.79 & 2.65 \\
\hline HPA8-30 & 360 & 336 & 0.23 & 0.19 & 0.83 & 2.61 \\
\hline HDA7-15 & 319 & 293 & 0.22 & 0.16 & 0.72 & 2.78 \\
\hline HDA7-30 & 291 & 268 & 0.20 & 0.15 & 0.75 & 2.76 \\
\hline HDA8-15 & 365 & 343 & 0.26 & 0.20 & 0.77 & 2.87 \\
\hline HDA8-30 & 356 & 326 & 0.25 & 0.18 & 0.72 & 2.75 \\
\hline
\end{tabular}

\subsection{Acid-base properties of the activated carbons}

The data from Table 3 show that the activated carbon adsorbents have surface of basic character as their $\mathrm{pH}$ values vary from 9.2 to 10.5 . The content of surface oxygen groups varies from 2.22 to $3.32 \mathrm{mmol} / \mathrm{g}$ and dominant among them are those of basic character. Therefore, the type and number of surface oxygen functional groups depend first of all on the temperature and time of activation. The highest total content of functional groups was determined on the surface of sample HPA8-30, while the lowest content of functional groups was found on the samples obtained by direct activation of the precursor at $700{ }^{\circ} \mathrm{C}$, that is samples HDA7-15 and HDA7-30, containing 2.22 and $2.24 \mathrm{mmol} / \mathrm{g}$ of functional groups. The data from Table 3 provide evidence that both temperature and time of activation influence the content of surface oxygen functional groups, while the influence of the method of activation is much smaller. For the majority of samples, an increase in the activation temperature from 700 to $800{ }^{\circ} \mathrm{C}$ and extension of the activation time from 15 to $30 \mathrm{~min}$ are conducive to generation of a greater number of basic groups and disappearance of groups of acidic character. The samples obtained by direct activation show a greater content of surface oxygen groups of acidic character than the analogous samples obtained in the two-stage process of activation.

\subsection{Sorption abilities of the activated carbons toward nitrogen dioxide}

Analysis of the data collected in Table 4 shows that the sorption capacity of the activated carbons studied towards nitrogen dioxide differ, depending on the parameters and the method of activation and conditions of the adsorption process, so it is difficult to select one sample of the best properties. The majority of activated carbon samples show greater adsorption capacity in dry conditions. The most effective adsorbent in dry conditions was sample HPA8-30, while the most effective in wet conditions was HDA8-15. The least effective adsorbents of nitrogen dioxide in dry and wet conditions were samples HDA8-15 and HDA8-30, obtained by direct activation at $800{ }^{\circ} \mathrm{C}$ for 15 or $30 \mathrm{~min}$. On the basis of the same data from Table 4, it was possible to confirm the earlier assumption that the activation temperature also influences the effectiveness of nitrogen dioxide removal by the samples studied. Irrespective of the variant of adsorption, almost all samples activated at $800{ }^{\circ} \mathrm{C}$ show greater sorption capacity than those activated at $700{ }^{\circ} \mathrm{C}$. The time of activation has only slight effect on
Table 3 Acid base properties of the activated carbons obtained

\begin{tabular}{lrlll}
\hline Sample & \multicolumn{1}{c}{ PH } & Acidic groups $(\mathrm{mmol} / \mathrm{g})$ & Basic groups $(\mathrm{mmol} / \mathrm{g})$ & Total content $(\mathrm{mmol} / \mathrm{g})$ \\
\hline HPA7-15 & 10.5 & 0.10 & 2.64 & 2.74 \\
HPA7-30 & 9.7 & 0.03 & 3.24 & 3.27 \\
HPA8-15 & 10.4 & 0.00 & 2.51 & 2.51 \\
HPA8-30 & 9.2 & 0.00 & 3.32 & 3.32 \\
HDA7-15 & 10.3 & 0.22 & 2.02 & 2.24 \\
HDA7-30 & 10.0 & 0.15 & 2.07 & 2.22 \\
HDA8-15 & 10.1 & 0.12 & 2.41 & 2.53 \\
HDA8-30 & 10.5 & 0.00 & 2.34 & 2.34 \\
\hline
\end{tabular}


Table $4 \mathrm{NO}_{2}$ breakthrough capacities in dry and wet conditions of the activated carbons obtained $\left(\mathrm{mg} / \mathrm{g}_{\text {ads }}\right)$

\begin{tabular}{lll}
\hline Sample & \multicolumn{2}{l}{$\mathrm{NO}_{2}$ breakthrough capacities $(\mathrm{mg} / \mathrm{g})$} \\
\cline { 2 - 3 } & Dry conditions & Wet conditions \\
\hline HPA7-15 & 37.3 & 34.0 \\
HPA7-30 & 40.4 & 34.5 \\
HPA8-15 & 44.9 & 37.5 \\
HPA8-30 & 46.0 & 44.7 \\
HDA7-15 & 32.0 & 52.6 \\
HDA7-30 & 29.2 & 41.6 \\
HDA8-15 & 31.0 & 55.1 \\
HDA8-30 & 36.7 & 28.9 \\
\hline
\end{tabular}

the sorption capacity of the samples towards $\mathrm{NO}_{2}$. The extension of the time of physical activation from 15 to 30 min only to a small degree (of a few mg of $\mathrm{NO}_{2}$ per $1 \mathrm{~g}$ of the adsorbent) improves the sorption capacity towards $\mathrm{NO}_{2}$ both in dry and in wet conditions. The extension of the time of the process of direct activation of the precursor deteriorated the sorption capacity of the sample in wet conditions of adsorption. Small deterioration of the sorption capacity with extension of the activation time was also noted for sample HDA7-15 when the adsorption process was performed in dry conditions.

Sorption capacities of most of the samples we studied are similar to those reported by Nowicki et al. (2010) for the carbon samples obtained by chemical activation of plum stones by $\mathrm{KOH}$. However, the procedure of obtaining activated carbon to be used as adsorbent should be further developed to reach the level of $140 \mathrm{mg} / \mathrm{g}$, reported by Bashkova and Bandosz (2009) for carbon samples modified with nitrogen.

Figure 1 presents the adsorption-desorption curves of $\mathrm{NO}_{2}$ recorded for the process in dry (Fig. 1a) and wet
(Fig. 1b) conditions. The majority of the curves have similar shapes, which suggests a similar mechanisms of adsorption of $\mathrm{NO}_{2}$ on the samples studied. For many samples, for some time of adsorption the concentration of $\mathrm{NO}_{2}$ is close to zero and the adsorption curve runs almost in parallel to the $\mathrm{x}$ axis. Then a breakthrough is observed and the particular curves differ in the time at which particular ppm values are recorded. For none of the samples a rapid increase in the concentration of nitrogen dioxide to the limiting values of $20 \mathrm{ppm}$ was observed in a short time.

The adsorption-desorption curves also imply that for the majority of samples, both in dry and wet conditions, at the stage of desorption a rapid decrease in the concentration of $\mathrm{NO}_{2}$ is observed. This fact suggests that most of the adsorbed nitrogen dioxide undergoes chemisorption on the activated carbon samples studied. It suggests that most of the adsorbed $\mathrm{NO}_{2}$ was strongly bonded through the surface oxygen functional groups of basic character that were able to react with $\mathrm{NO}_{2}$.

While performing sorption capacity measurements, also the concentration of nitrogen oxide was recorded. NO can be formed as a result of $\mathrm{NO}_{2}$ reduction in the reactions with the surface functional groups on the carbon samples. The character of curves presented in Fig. 2a and b implies that the carbon samples studied show different abilities to reduce $\mathrm{NO}_{2}$ to NO. The rate of such reduction depends considerably on the conditions of adsorption and is the highest in wet conditions. This observation means that the maximum concentration of $\mathrm{NO}(200 \mathrm{ppm})$ is reached in much shorter time in the presence of moisture in the system.

\subsection{Sorption abilities of activated carbons toward $\mathrm{H}_{2} \mathrm{~S}$}

The samples studied were also tested as adsorbents of hydrogen sulphide and similarly as noted for adsorption of $\mathrm{NO}_{2}$, the sorption capacity of the samples depended on the
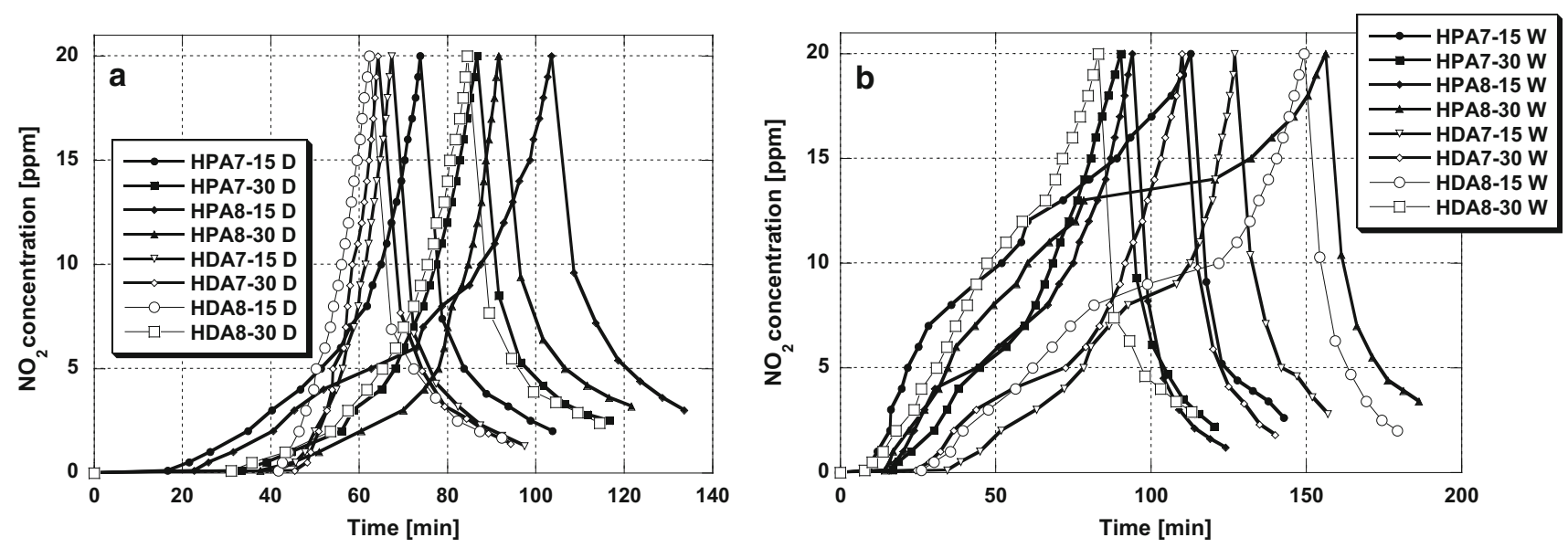

Fig. $1 \mathrm{NO}_{2}$ breakthrough curves obtained during adsorption in dry conditions (a) and wet conditions (b) 

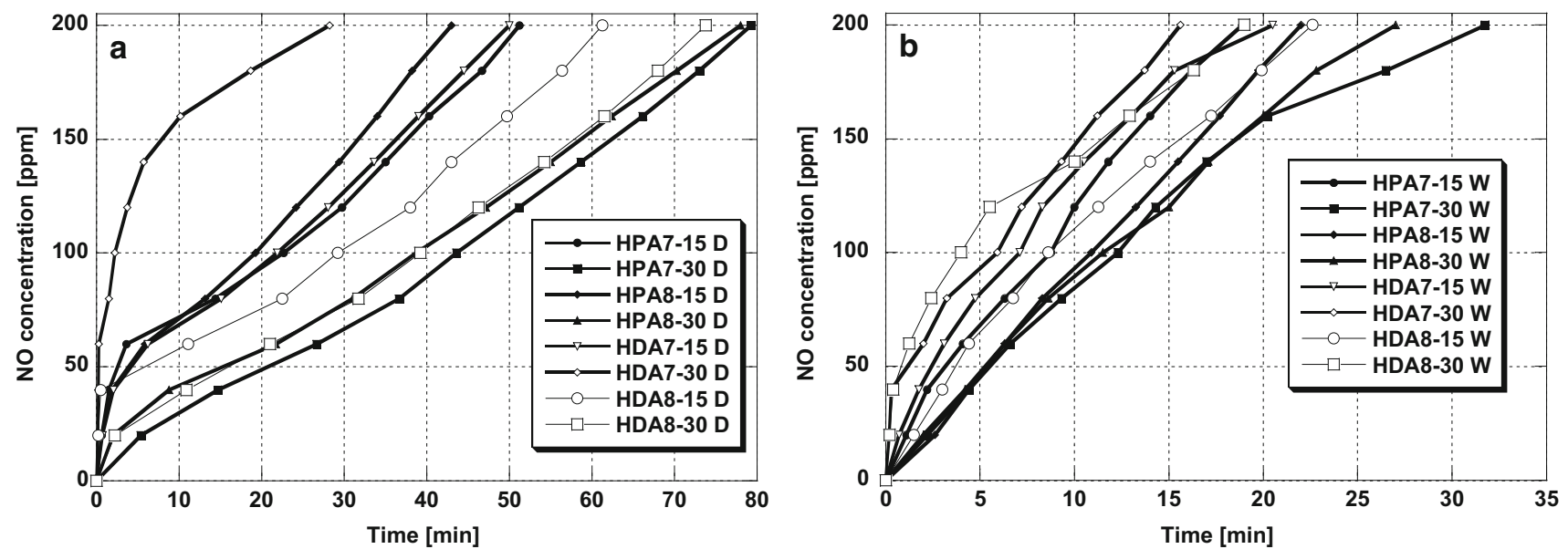

Fig. 2 NO emission curves obtained during adsorption in dry (a) and wet (b) conditions

temperature and time of activation. As follows from analysis of the data collected in Table 5, the most effective adsorbent of $\mathrm{H}_{2} \mathrm{~S}$ was sample HPA7-15, whose sorption capacity in dry and wet conditions was 11.0 and $39.0 \mathrm{mg} / \mathrm{g}$, respectively. The least satisfying results were obtained for the sample obtained by direct activation of precursor at $700{ }^{\circ} \mathrm{C}$ for $30 \mathrm{~min}$, whose sorption capacity towards $\mathrm{H}_{2} \mathrm{~S}$ was $\sim 5$ and $\sim 12 \mathrm{mg} / \mathrm{g}$ in dry and wet conditions, respectively. The activation temperature has a significant effect on the sorption capacity towards $\mathrm{H}_{2} \mathrm{~S}$, which was particularly pronounced for the samples obtained by direct activation-with the temperature increase from 700 to $800{ }^{\circ} \mathrm{C}$, and when adsorption took place in wet conditions, the sorption capacity increased twice. The time of activation also influences the ability of $\mathrm{H}_{2} \mathrm{~S}$ removal, extension of the activation time from 15 to $30 \mathrm{~min}$ increased the sorption capacity of samples HPA8-15 D and HDA8-15 D, had a very small influence on the capacity of HDA7-15 W, while for the other samples it was not beneficial and even caused a decrease in the sorption capacity. As mentioned above, also the conditions of adsorption influenced the

Table $5 \mathrm{H}_{2} \mathrm{~S}$ breakthrough capacities in dry and wet conditions of the activated carbons obtained $\left(\mathrm{mg} / \mathrm{g}_{\text {ads }}\right)$

\begin{tabular}{lll}
\hline Sample & \multicolumn{2}{c}{$\mathrm{H}_{2} \mathrm{~S}$ breakthrough capacities $(\mathrm{mg} / \mathrm{g})$} \\
\cline { 2 - 3 } & Dry conditions & Wet conditions \\
\hline HPA7-15 & 11.0 & 39.0 \\
HPA7-30 & 5.9 & 24.0 \\
HPA8-15 & 6.0 & 32.3 \\
HPA8-30 & 8.4 & 25.0 \\
HDA7-15 & 10.9 & 12.5 \\
HDA7-30 & 5.2 & 12.3 \\
HDA8-15 & 8.3 & 26.1 \\
HDA8-30 & 9.7 & 25.7 \\
\hline
\end{tabular}

sorption capacity towards $\mathrm{H}_{2} \mathrm{~S}$, for all samples the sorption capacity in wet conditions was higher.

In our previous work (Kazmierczak-Razna et al. 2015a) we used activated carbons prepared from sawdust pellets from coniferous wood to remove hydrogen sulphide, the highest sorption capacity was $6.2 \mathrm{mg} / \mathrm{g}$. It shows that we were able to optimize the conditions for the activation process and obtain materials characterised by higher sorption capacities reaching $39.0 \mathrm{mg} / \mathrm{g}$. Unfortunately, these results are very modest when compared to those obtained for other carbonaceous sorbents, especially as far as $\mathrm{H}_{2} \mathrm{~S}$ removal is concerned. The reported sorption capacity achieved towards this gas exceeded $100 \mathrm{mg} / \mathrm{gads}$ (Bandosz 2002), and for some materials—even $200 \mathrm{mg} / \mathrm{g}$ (Nowicki et al. 2014).

The adsorption-desorption curves recorded for all samples are presented in Fig. 3a and b and their character is similar. They are composed of a flat section when the adsorption curve coincides with the $\mathrm{x}$ axis and then show a characteristic point corresponding to breakthrough of the bed and from this point on the concentration of $\mathrm{H}_{2} \mathrm{~S}$ increases to the limit value of $100 \mathrm{ppm}$. For the samples showing low sorption capacities towards $\mathrm{H}_{2} \mathrm{~S}$, this fragment of the adsorption curve is close to a line ascending in parallel to the y axis, while for the other samples (e.g. HDA7-15 D, HDA7-15 W, HPA8-15 W) this section of the curve has a more gentle character.

Analysis of the adsorption-desorption curves indicates that for all samples, in both dry and wet conditions, at the stage of desorption a rapid decrease in $\mathrm{H}_{2} \mathrm{~S}$ concentration is observed. This fact suggests that the majority of $\mathrm{H}_{2} \mathrm{~S}$ that was adsorbed was in fact strongly chemisorbed by the surface functional groups on the samples studied.

\subsection{Iodine number}

As follows from the data presented in Fig. 4, the activated carbons are characterised by the iodine number varied from 

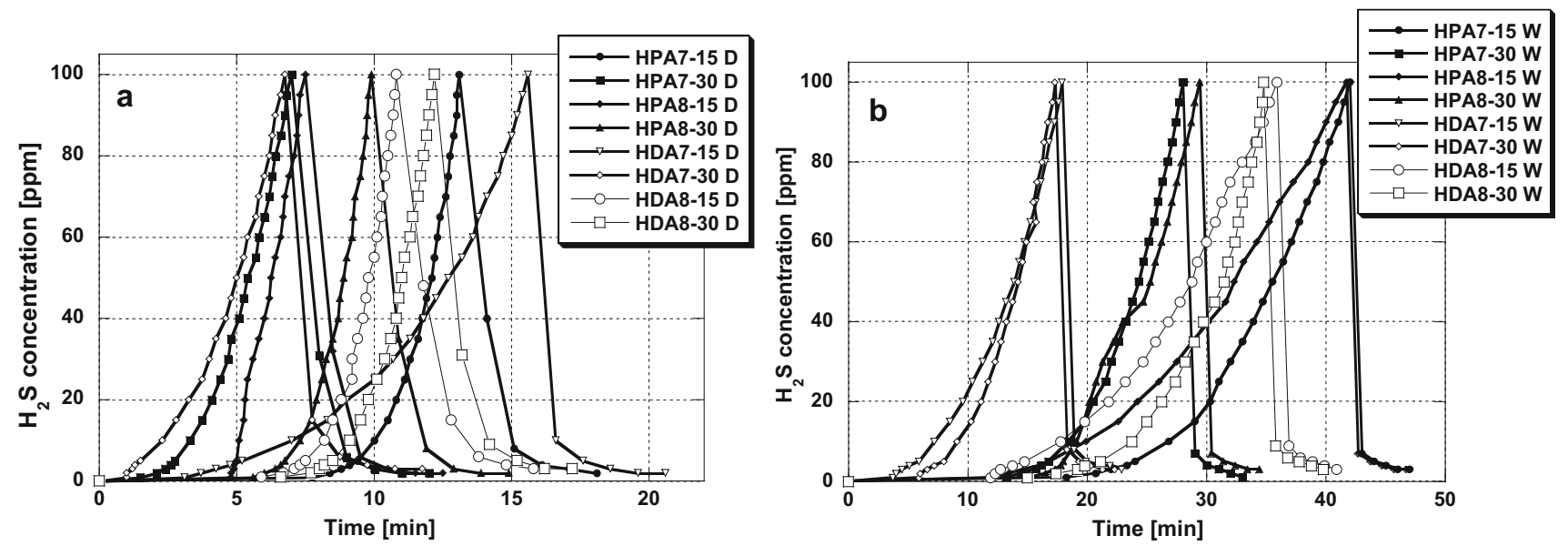

Fig. $3 \mathrm{H}_{2} \mathrm{~S}$ breakthrough curves obtained during adsorption in dry conditions (a) and wet conditions (b)

Fig. 4 Adsorption of iodine onto activated carbons

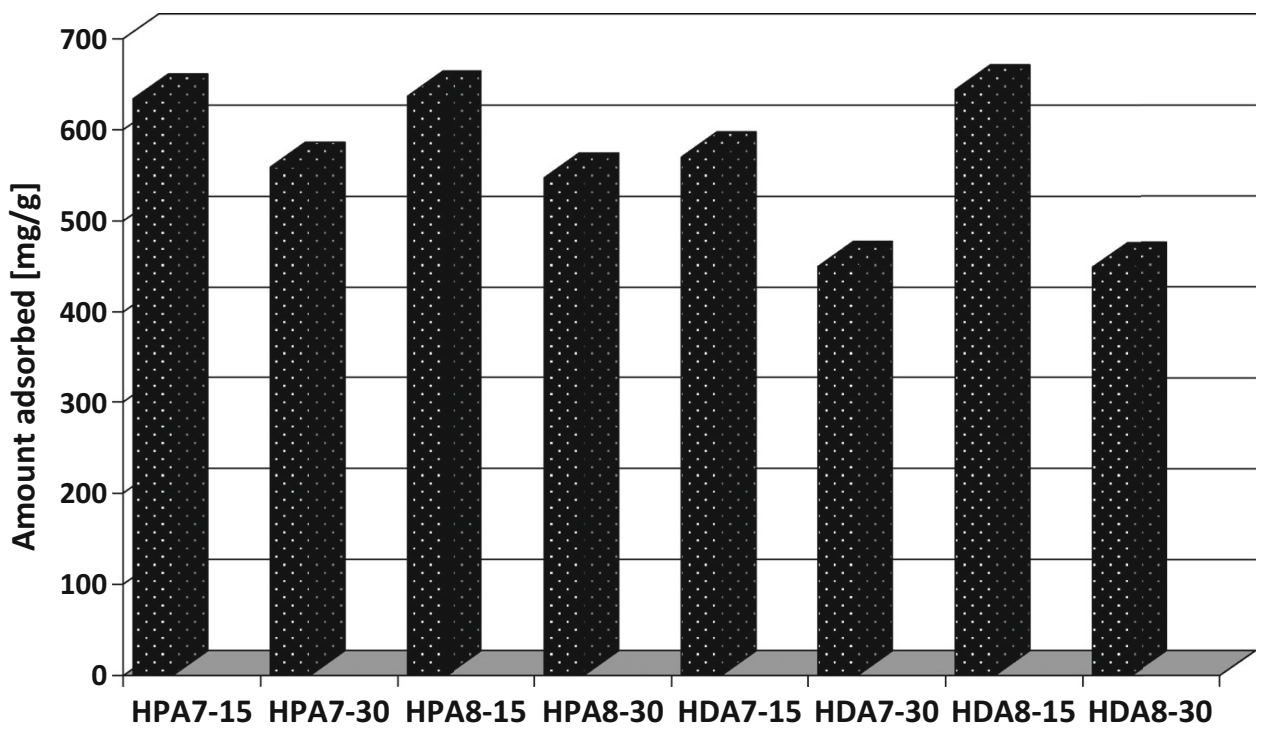

449 to $644 \mathrm{mg} / \mathrm{g}$, so lower than the commercial adsorbents available on the market. The sorption capacity of the activated carbon samples studied towards iodine was found to change in response to the activation temperature and time. The most effective adsorbent (nearly $644 \mathrm{mg} / \mathrm{g}$ ) was the sample obtained by direct activation of the precursor at $800{ }^{\circ} \mathrm{C}$ for $15 \mathrm{~min}$ (HDA8-15), whose sorption capacity towards iodine was by almost $200 \mathrm{mg} / \mathrm{g}$ greater than that of the sample obtained by direct activation at the same temperature but for $30 \mathrm{~min}$ (HDA8-30). Irrespectively of the temperature of activation, the samples subjected to activation for $15 \mathrm{~min}$ had higher iodine numbers. Most probably it is a consequence of a better developed surface area in the samples activated for 15 rather than $30 \mathrm{~min}$ (Table 2). The increase in the activation temperature, irrespectively of the activation method, had no significant influence on the iodine adsorption. For samples HPA7-15 and HPA8-15 the higher temperature increased the adsorption capacity by only $3 \mathrm{mg} / \mathrm{g}$, while the sorption capacity of samples HPA7-30 and HPA8-30 towards iodine decreased for activation at the higher temperature. Similar relations were noted for the adsorbents obtained by direct activation of the precursor.

\section{Conclusions}

It has been shown that the materials obtained by direct activation of low quality hay or by pyrolysis of this precursor followed by physical activation by microwave radiation are adsorbents show interesting physicochemical properties. Although the materials obtained are characterised by not much developed surface area and porous structure, thanks to the basic nature of their surface they 
can be attractive adsorbents for removal of acidic pollutants such as nitrogen dioxide and hydrogen sulphide. The sorption capacity of the adsorbents obtained depend on the temperature, time and method of activation as well as on the conditions of adsorption, therefore it is difficult to select one sample of the optimum sorption properties.

Open Access This article is distributed under the terms of the Creative Commons Attribution 4.0 International License (http://crea tivecommons.org/licenses/by/4.0/), which permits unrestricted use, distribution, and reproduction in any medium, provided you give appropriate credit to the original author(s) and the source, provide a link to the Creative Commons license, and indicate if changes were made.

\section{References}

Adib, F., Bagreev, A., Bandosz, T.J.: Effect of surface characteristics of wood-based activated carbons on adsorption of hydrogen sulfide. J. Colloid Interface Sci. 214(2), 407-415 (1999)

Ahmad, A.A., Hameed, B.H.: Fixed-bed adsorption of reactive azo dye onto granular activated carbon prepared from waste. J. Hazard. Mater. 175, 298-303 (2010)

Bandosz, T.J.: On the adsorption/oxidation of hydrogen sulfide on activated carbons at ambient temperatures. J. Colloid Interface Sci. 246(1), 1-20 (2002)

Bashkova, S., Bandosz, T.J.: The effects of urea modification and heat treatment on the process of $\mathrm{NO}_{2}$ removal by wood-based activated carbon. J. Colloid Interface Sci. 333(1), 97-103 (2009)

Benadjemia, M., Millière, L., Reinert, L., Benderdouche, N., Duclaux, L.: Preparation, characterization and methylene blue adsorption of phosphoric acid activated carbons from globe artichoke leaves. Fuel Process. Technol. 92, 1203-1212 (2011)

Ferrero, F.: Dye removal by low cost adsorbents: hazelnut shells in comparison with wood sawdust. J. Hazard. Mater. 142, 144-152 (2007)

Guo, B., Chang, L., Xie, K.: Adsorption of carbon dioxide on activated carbon. J. Nat. Gas Chem. 15(3), 223-229 (2006)

Hauchhum, L., Mahanta, P.: Carbon dioxide adsorption on zeolites and activated carbon by pressure swing adsorption in a fixed bed. Int. J. Energy Environ. Eng. 5, 349-356 (2014)

Hesas, R.H., Daud, W.M.A.W., Sahu, J.N., Arami-Niy, A.: The effects of a microwave heating method on the production of activated carbon from agricultural waste: a review. J. Anal. Appl. Pyrol. 100, 1-11 (2013)

Jiang, J., Ma, X.-Q.: Experimental research of microwave pyrolysis about paper mill sludge. Appl. Thermal Eng. 31, 3897-3903 (2011)

Kazmierczak-Razna, J., Gralak-Podemska, B., Nowicki, P., Pietrzak, R.: The use of microwave radiation for obtaining activated carbons from sawdust and their potential application in removal of $\mathrm{NO}_{2}$ and $\mathrm{H}_{2} \mathrm{~S}$. Chem. Eng. J. 269, 352-358 (2015a)

Kazmierczak-Razna, J., Nowicki, P., Pietrzak, R.: The use of microwave radiation for obtaining activated carbons enriched in nitrogen. Powder Technol. 273, 71-75 (2015b)

Li, W., Zhang, L.-B., Peng, J.-H., Li, N., Zhu, X.-Y.: Preparation of high surface area activated carbons from tobacco stems with $\mathrm{K}_{2} \mathrm{CO}_{3}$ activation using microwave radiation industrial. Crop. Product. 27, 341-347 (2008)
Liu, Q.-S., Zheng, T., Li, N., Wang, P., Abulikemu, G.: Modification of bamboo-based activated carbon using microwave radiation and its effects on the adsorption of methylene blue. Appl. Surf. Sci. 256(10), 3309-3315 (2010)

Malik, P.K.: Dye removal from wastewater using activated carbon developed from sawdust: adsorption equilibrium and kinetics. J. Hazard. Mater. B 113, 81-88 (2004)

Malik, D.J., Strelko Jr, V., Streat, M., Puziy, A.M.: Characterisation of novel modified active carbons and marine algal biomass for the selective adsorption of lead. Water Res. 36, 1527-1538 (2002)

Nethaji, S., Sivasamy, A., Thennarasu, G., Saravanan, S.: Adsorption of Malachite Green dye onto activated carbon derived from Borassus aethiopum flower biomass. J. Hazard. Mater. 181, 271280 (2010)

Nowicki, P., Pietrzak, R.: Effect of ammoxidation of activated carbons obtained from sub-bituminous coal on their $\mathrm{NO}_{2}$ sorption capacity under dry conditions. Chem. Eng. J. 166, 1039-1043 (2011)

Nowicki, P., Skibiszewska, P., Pietrzak, R.: $\mathrm{NO}_{2}$ removal on adsorbents prepared from coffee industry waste materials. Adsorption 19(2-4), 521-528 (2013)

Nowicki, P., Skibiszewska, P., Pietrzak, R.: Hydrogen sulphide removal on carbonaceous adsorbents prepared from coffee industry waste materials. Chem. Eng. J. 248, 208-215 (2014)

Nowicki, P., Supłat, M., Przepiórski, J., Pietrzak, R.: $\mathrm{NO}_{2}$ removal on adsorbents obtained by pyrolysis and physical activation of corrugated cardboard. Chem. Eng. J. 195-196, 7-14 (2012)

Nowicki, P., Pietrzak, R., Wachowska, H.: Comparison of physicochemical properties of nitrogen-enriched activated carbons prepared by physical and chemical activation of brown coal. Energy Fuel 22, 4133-4138 (2008)

Nowicki, P., Pietrzak, R., Wachowska, H.: Influence of metamorphism degree of the precursor on preparation of nitrogen enriched activated carbons by ammoxidation and chemical activation of coals. Energy Fuel 23, 2205-2212 (2009)

Nowicki, P., Wachowska, H., Pietrzak, R.: Active carbons prepared by chemical activation of plum stones and their application in removal of $\mathrm{NO}_{2}$. J. Hazard. Mater. 181, 1088-1094 (2010)

Pal, J., Deb, M.K.: Efficient adsorption of congo red dye from aqueous solution using green synthesized coinage nanoparticles coated activated carbon beads. Appl. Nanosci. 4, 967-978 (2014)

Pietrzak, R., Bandosz, T.J.: Activated carbons modified with sewage sludge derived phase and their application in the process of $\mathrm{NO}_{2}$ removal. Carbon 45, 2537-2546 (2007)

Puziy, A.M.: Methods of production, structure, and physicochemical characteristics of phosphorylated carbon adsorbents. Theor. Exp. Chem. 47, 277-291 (2011)

Remya, N., Lin, J.-G.: Current status of microwave application in wastewater treatment-a review. Chem. Eng. J. 166, 797-813 (2011)

Sych, N.V., Trofymenko, S.I., Poddubnaya, O.I., Tsyba, M.M., Sapsay, V.I., Klymchuk, D.O., Puziy, A.M.: Porous structure and surface chemistry of phosphoric acid activated carbon from corncob. Appl. Surf. Sci. 261, 75-82 (2012)

Wu, F.-C., Tseng, R.-L.: High adsorption capacity NaOH-activated carbon for dye removal from aqueous solution. J. Hazard. Mater. 152, 1256-1267 (2008)

Yuen, F.K., Hameed, B.H.: Recent developments in the preparation and regeneration of activated carbons by microwaves. Adv. Colloid Interface Sci. 149, 19-27 (2009) 